\title{
Media labeling versus the US disability community identity: a study of shifting cultural language
}

Beth Haller*, Bruce Dorries and Jessica Rahn

Towson University, USA; Mary Baldwin College, USA

This study examines disability terminology to explore how the news media frame cultural representations of the disability community. More specifically, the paper examines the impact of the Americans with Disabilities Act on journalist's language choices about disability topics. A content analysis of news stories using disability terms in The Washington Post and The New York Times during the past decade was conducted. The paper illustrates that disability community identity continues to be formed, transformed and maintained through news media presentations of disability terminology. The paper argues that the US Disability Rights Movement had some success during the 1990s in putting forth language that advances its aims, though the study also suggests that some journalists continue to use terms that perpetuate limiting, narrow stereotypes about people with disabilities.

Language has always had power to define cultural groups, and the past 15 years have ushered in a new era in the USA for framing disability via the media because of the passage of the Americans with Disabilities Act (ADA). The Act, primarily crafted by disability rights activists, tried to bring about significant change in the USA by eliminating many societal barriers that people with disabilities faced.1 In light of the law's effort to change US society, this study assesses how or if the US news media have absorbed any of these shifts in US society because of the ADA. Specifically, the study looks at the terms the media use to refer to people with disabilities. Numerous studies already exist that have assessed other aspects of media coverage of disability issues (Clogston, 1989, 1990, 1991; Cumberbatch \& Negrine, 1991; Haller, 1993, 1995, 1999a, 1999b, 2000; Johnson, 2000; Barnartt et al., 2001). Our focus on disability terminology is specifically narrow because the US Disability Rights Movement has been advocating appropriate language use for a number of decades; like all social groups, they contend that what they are called is part of their identity as people with disabilities and they should decide these terms. In addition, we argue that looking at terminology is significant because it gives us a way to understand whether a more disability-aware US society is manifesting itself in changes in media behaviors as well. We suggest that even something as mundane as the words used to refer to a group are important because they have ramifications both for the self-perception of people with disabilities and what the general public believes about disability. 
This study assesses the impact of disability rights efforts as the movement embodies what Longmore (1995) termed 'The second phase', a move toward strengthening disability culture through self-definition. Phase one shifted people with disabilities into the mainstream by outlawing discrimination and mandating access - it argued for social inclusion. In phase two, both activists and theorists consider media coverage and the language used by journalists to represent disability issues to be central to this process.

\section{Language, framing and disability identity}

The concept of framing gives a useful perspective for this study because it 'offers a way to describe the power of a communicating text' (Entman, 1993, p. 51). Media texts contain frames, 'which are manifested by the presence or absence of certain keywords, stock phrases, stereotypical images, sources of information, and sentences that provide thematically reinforcing clusters of facts or judgments' (p. 52). Through their selection of certain words over others, the media make certain terms more salient or memorable for their audiences. This study looks at one small, but powerful, element of media framing of people with disabilities - how they are referred to as a social group.

Language about groups engaged in a social movement has always been a site of contested terrain (Allen, 1990; Smith, 1992; Stewart et al., 1994). As society changes, certain terminology falls out of favor, such as the continuum in the USA from 'colored' to Black to African Americans. The dominant culture, or majority, generally resists these language shifts, often derogatorily labeling them as 'just political correctness' (Reiser, 2001). Often the media have been sluggish in assimilating new terms. Accordingly, activists for social movements have had to push their language changes into media frames, usually with only moderate success.

For decades, both overt and implied references to people with disabilities have concerned disabilities studies scholars and the Disability Rights Movement because they are so integral to disability culture and identity. Disability policy consultant June Isaacson-Kailes explains: 'A significant element in the struggle for basic human rights is what people call themselves ... Disability culture is the commonality of the experience of living with a disability, and language is one of the keys to acknowledging this culture' (1985, p. 5). British disability studies scholar Mairian Corker (1998, p. 225) explained "that the process of defining is bound up in "matters of identity" and therefore with action, political and otherwise, which is taken'.

For example, since the 1980s, the Disability Rights Movement has been trying to move from the term 'handicapped', which many feel associates people with disabilities with beggars (Barnes, 1992) (although recent research reports that derivation of the word is inaccurate, (Crowley \& Crowley, 1999)), to 'people with disabilities', which is known as 'people-first' terminology. The passage of the ADA tried to push out the 
term 'handicapped' because activists were involved in writing the legislation and made sure it included the 'people-first' terminology. As political scientist Art Blaser (2002, p. 26) notes: 'With the term "disability," we have a major advantage because it's been used for decades, and was used by an almost unanimous Congress in passing the Americans with Disabilities Act'. The preferred disability terminology was a way that activists infused some disability culture into the ADA.

Disability culture as an outgrowth of identity is imbedded with political activism. Since the 1960s, US disability rights activists have advocated for a 'frame' in which society views them and their issues as a legitimate minority group that faces societal barriers and discrimination (Fleischer \& Zames, 2001). Journalist Joseph Shapiro (1993), in his book, No pity. People with disabilities forging a new civil rights movement, explained that the recent history of the US Disability Rights Movement had an emphasis on activists coming together to push for federal legislation such as the Rehabilitation Act in the 1970s, which was a precursor to the ADA. Johnstone (2004) argues that formalized education and the recent growth of Disability Studies college programs forged modern disability identity. He argues that disability identity is becoming a formalized part of US society:

The common voice and other empowering identities for people with disabilities are emergently receiving support by formalized structures. These structures publicize and communicate the notion of disability identity to the larger population. Messages such as: people come before disability, disability as a social and political issue, and promotion of disability culture are found in formal education, organizations and communications. ... Publications have institutionalized the disabled identity into mainstream society. Narrative accounts of disability have brought the reality and complexity of disability to a wide readership, some with no previous experience with the notion of identity. (Johnstone, 2004, online)

The narrative accounts to which Johnstone refers are personal accounts within memoirs and other books about personal stories, rather than the mass media. Media reports, too, prefer these personal stories that are fashioned into narratives of 'overcoming the odds' or exceptional accomplishments (Thomson, 2001); however, in the hands of the media, these narratives serve to undermine disability identity with their syrupy messages infused with pity. Therein lays the tension between the internal pride, identity and culture of the Disability Rights Movement and the misinterpretation by the wider society, represented by the media, that active people with disabilities are 'inspirational' or are 'superior' in the face of 'tragedy'. The Disability Rights Movement is trying to move forward a serious political agenda, and the media focus on blind people who go bowling or a teen with a severe facial disfigurement who copes with life gracefully (Haller, 2001).

These issues underpin the discussions of disability terminology, the terms preferred by the Disability Rights Movement, and what is actually used by the news media. For 
decades, publications intended primarily for the disability community have noted that much media coverage of disability issues often does not include language that reflects current usage within the community (Birenbaum, 2000). The disability rights magazine, The Disability Rag, noted in 1990, the year the ADA passed, that 'even as we begin to see more "real" disability reporting', media coverage illustrates a seeming lack of awareness and context when addressing disability issues (p. 7).

Some disability activists criticize the Disability Rights Movement for the 'media problem', saying it stems from lack of a single, national voice for the movement, lack of training in conveying the importance of language choice to the media, as well as lack of framing issues in ways that emphasize people-first and other standards for addressing disability issues ('What we say', Ragged Edge, 1999). However, many in the disability community say they are hampered by the negative associations that already exist inherently in the words 'disabled' and 'disability'. As activist Bill Bolt argued in Ragged Edge (formerly The Disability Rag):

The name that we've insisted on for ourselves - the word 'disabled' - sends journalists into a tailspin. If we are 'disabled,' that is, 'without abilities,' then what is this demand for equal employment, journalists likely think. On the other hand, if we can work with only minimal special arrangements, then why do we need all kinds of government funds to live on? (Bolt, 1999, p. 24)

US disability studies scholar Simi Linton, in her book Claiming Disability (1998), also notes the problematic nature of the prefix 'dis', which connotes separation or taking apart. It has numerous denotative meanings:

absence of, as in disinterest; opposite of, as in disfavor; undo, do the opposite of, as disarrange; and deprive of, as in disenfranchise. The Latin root dis means apart, asunder. Therefore, to use the verb disable, means in part to deprive of capability or effectiveness. The prefix creates a barrier, cleaving in two, ability and its absence, its opposite. Disability is the 'not' condition, the repudiation of ability. (Linton, 1998, p. 30)

Yet, disability activists and scholars also counter that any new terms promoted by the movement, regardless of journalists' practices and intentions, would soon be stigmatized by the larger culture; therefore, efforts should concentrate on improving perceptions of people with disabilities. Over time such efforts might erase the stigma associated with 'disabled' and similar terms. 'Old habits die hard, in part because they are reinforced by the media', notes Blaser, adding, 'But they do die' (2002, p. 25). He disagrees with those who consider negativity inherent in the words 'disabled' and 'disability' and public perception of the terms as unalterable. Decades of work by the movement has been changing the meaning of disability, much as African Americans transformed the term 'black' and the gay and lesbian movements altered 'queer'. Blaser says the disability community is fighting the same fight as these other social groups: 'I' $m$ not convinced that our task in changing language is 
more difficult than Malcolm X's was, or unusually difficult when compared with other groups'. But I'll really be surprised if it's not still being fought by my children's grandchildren' (p. 26).

Some rhetorical and linguistic theorists agree with Blaser. Although disability has long been equated with tragedy, suffering and weakness in the minds of many in the general public, the Disability Rights Movement continues to battle for a new understanding of the word over many years or decades to come. British disability studies scholar Jenny Corbett (1996) maintains that language, as a primary source of power and control, must be contested - words, for example, disabled, must be won by the 'voice of enlightened modernity' in debates about political correctness, so that old usages are redefined. Language that retains a metaphorical suffering, pathos and dependency needs to be challenged. For example, by reclaiming 'cripple', disabled activists take the image in their identity that scares outsiders and make it a source of militant pride.

In the same vein, Linton maintains that wrestling for control of language and attempting to reassign the meaning of terminology used to describe disability and disabled people is vital to show how language reinforces the dominant culture's views of disability. She argues that since roughly 1980, people with disabilities themselves have gained more control over definitional issues, including within the news media. 'Less subtle, idiomatic terms for people with disabilities, such as: "cripple", "vegetable", "dumb", "deformed", "retard", and "gimp" have generally been expunged from public conversation though they appear in discourse ... Cripple as a descriptor of disabled people is considered impolite, but the word had retained its metaphoric vitality, as in "the expose in the newspaper crippled the politician's campaign"' (Linton, 1998, p. 16). However, Ben-Moshe says that even the metaphoric use of disability terms stigmatize people with disabilities:

When we use terms like 'retarded,' 'lame,' or 'blind' - even if we are referring to acts or ideas and not to people at all - we perpetuate the stigma associated with disability. By using a label, which is commonly associated with disabled people to denote deficiency, a lack, or an ill-conceived notion, we reproduce the oppression of people with disabilities. (Ben-Moshe, 2005, pp. 108-109)

Other types of negative terminology that remain in the media reinforce a 'sick role' or the medicalization of the disability identity. The news media sometimes refer to people who had contracted polio earlier in life as having been 'stricken' with polio. People with AIDS are sometimes referred to as 'AIDS sufferers', 'suffering from' AIDS, 'AIDS patients', or 'victims of' AIDS. Activist Jo Bower explains how dislike of this language has been a bond between many people with different disabilities: 'All of us have rejected the terms "victim" and "patient" to describe our relationship to our conditions and instead have chosen terms with dignity, which underline our personhood primarily and our condition second, as in people with HIV or people with 
disabilities' (Bower, 1994, p. 8). Linton adds that phrases found in media writing, such as, 'the man is a victim of cerebral palsy', makes the disease an agent that acts upon a helpless victim. Use of 'victim' implies criminal action while also giving life, power and intention to the condition while rendering the person passive and helpless. Problematic assumptions also apply to terms such as 'suffering from' or 'afflicted with'. If the person's condition is germane to the story, language such as 'he has cerebral palsy', serves as a better descriptor because it doesn't impose extraneous meanings while more accurately reporting the facts.

With regard to the stereotyping phrases 'wheelchair bound' or 'confined to a wheelchair', Linton notes that these common descriptions in the print media grant more power to the chair than the person. To report instead that someone uses a wheelchair 'not only indicates the active nature of the user and the positive way that wheelchairs increase mobility and activity but recognizes that people get in and out of wheelchairs for different activities: driving a car, going swimming, sitting on the couch, or occasionally, for making love' (1998, p. 27).

Peters (1999) believes such sociolinguistic changes that aim to empower people with disabilities will result in the most positive consequences. Media framing though negative terminology can even prove detrimental to the self-images of people with disabilities. Such practices result in significant negative consequences and barriers to productive living. Many disabled people (particularly youth) internalize labels and language used to inculcate them as passive recipients of state welfare, Peters says. 'They develop a false consciousness as they internalize the oppressors' image conveyed through language. This cultural invasion leads many disabled people to a silent world of passive acceptance where they adapt to the status quo ...' (p. 103). Corker reaches similar conclusions, but optimistically notes that around the world disabled people have been using language to create a 'new disability discourse', and that issues of linguistic and cultural difference go well beyond "nice" words and the "nasty" words relating to disability that are in cultural circulation' (p. 193). To effectively produce sociocultural change, the US Disability Rights Movement continues to directly engage media and other powerful institutions by calling attention to the linguistic frames used to characterize disability.

\section{The significance of the ADA as an agent of change}

The first director of the National Council on Disability recalled what he said was the most important media event in the US Disability Rights Movement - the international Cable News Network (CNN)'s decision to carry the signing of the Americans with Disabilities Act live on TV. He said this one media event may have even been the most significant aspect of the ADA because 'laws are as much perception as reality' (Fleischer \& Zames, 2001, p. 210). This one event thrust disability rights before the eyes of a huge TV audience and in turn, got journalists thinking about disability 
issues as a legitimate news story.

This study of disability terminology selected a time frame of analysis after the passage of the ADA because as strong disability rights legislation, it had the potential to shift US society to be more barrier-free. Linguistically, the ADA helped create a message about people with disabilities that contrasted with narrow stereotypes and misleading myths of the past. The Disability Rights Movement had long been battling a medical or social welfare representation, that the media often reinforced, which views disability as a physical problem alone residing within an individual (Scotch, 1988). The activists have long pushed for the disability rights model of representation (similar to the British disability studies Social Model), which acknowledges physical differences while shifting the focus from the disabled individual as 'the problem' to societies that have yet to modify their architectural, occupational, educational, communication and attitudinal environments to accommodate everyone.

One of the greatest accomplishments of activists in getting the ADA passed was maintaining the narrative of civil rights and minority group politics in the law (Watson, 1993). The disability community established a strong narrative for the ADA: "That its protections were an issue of civil rights rather than a charitable obligation or some other rationale" (Watson, 1993, p. 29). The ADA was 'civil rights regardless of cost' (p. 30). With that narrative secure in the legislative language, government sources and disability-related sources gave the news media the same information. For decades, disability has been defined and framed by government through legislation on war veterans, rehabilitation, education and social security (Liachowitz, 1988), but this time the Disability Rights Movement had the rhetorical power to craft the ADA. As Scotch explains: 'The disability rights movement is one in which the way an issue was framed had serious effects on both movement participation and the ability of the movement to influence public policies' (1988, p. 168).

Haller (1999a, 1999b, 1995, 2000) has argued that the ADA and the US news media's coverage of it in the early years helped place the disability rights model before the broader public. Disability rights activists helped construct the wording of the ADA and with those words flowing through the US government to the media, a more rights-oriented frame of disability was presented to the public. Therefore, in one sweeping legislative action, the disability rights perspective was forced onto the media radar and the public agenda of the USA, possibly shifting the media frames of people with disabilities.

It should be noted that mass media may be even more significant in presenting people with disabilities and their issues because many Americans have less interpersonal contact with people with disabilities because of barriers that still exist in society. Much of society is exposed to views of disability almost exclusively through mass media (Louis Harris and Associates Inc., 1991). 
The media's coverage of the ADA probably promoted an awareness of the preferred terminology with which to refer to people with disabilities because the news media parroted the government's 'people-first' language in the coverage (Haller, 1995). Past research has confirmed that most journalists give high credibility to government information (Olien et al., 1989). For example, after the ADA, some local or state governments embraced 'people-first' language. Pennsylvania Governor Robert P. Casey mandated 'people-first' language in an executive order barring discrimination based on disability in state government (1992). Examples of peoplefirst language are saying 'a professor with a disability' rather than 'a handicapped professor', saying 'uses a wheelchair' not 'confined to a wheelchair', or 'non-disabled' not 'normal' (Temple University Institute on Disabilities, 1992).

Therefore, this study seeks to understand whether this carefully crafted disability rights wording for ADA has begun to influence how two elite members of the US news media refer to people with disabilities.

\section{Analysis of disability terminology in two elite newspapers}

This study conducted a content trend analysis of two major US newspapers to look at disability terminology use over a ten-year period. The New York Times and Washington Post were selected primarily because of their large circulations and their prominence as agenda-setting, elite media in the USA. Although content analysis makes judgments about content, not media effects, the assumption is that elite media act as opinion leaders about disability information and disability terminology in their stories. Most Americans say they use elite news media for information and these media are extremely important to them, according to a 1996 Gallup poll. Although Americans use more network TV news as a source, they are more likely to value the information from newspapers (Schwartz, 1996).

All the print stories in the data set were collected from the Lexis-Nexis newspaper database. The search terms used were: 'disabled', 'disability', 'disabilities', 'handicapped', 'cripple' and 'crippled'. All the stories with these terms were evaluated. The unit of analysis was an individual newspaper story, not the terms, so one story might contain several different terms. Also, any stories that used metaphorical disability terms that were not connected to disability issues or people with disabilities were eliminated from the sample. Restaurant listings referring to 'handicapped accessible' facilities were eliminated. Also, any story in which the only use of the disability term was in an organization's name, such as the President's Committee on the Employment of People with Disabilities, was eliminated because the use of the term reflected no decision-making on the part of the newspaper. However, stories that had any disability term, even one reference unconnected to the rest of the story, were still included in the sample. The limitation of this search is that it missed stories about individual disabilities if there was no use of one of these terms, such as a story about 
a blind person that never used the term 'disability'. However, because the focus of this study is specifically disability terminology, using the six terms above was the most viable option.

The samples consisted of stories in the two newspapers during October and November 1990, 1995 and 2000. October and November were selected because October is Disability Awareness Month and during November most activities in American life continue to occur, such as school and government meetings. Tables 1 illustrates the number of stories per publication per year that were evaluated. The analysis of the terminology looked at the ways in which the terms were used, such as 'The disabled', 'disabled person/people', disability as a noun, 'people with disabilities', 'handicapped', 'cripple' or 'crippled'. The study does not pretend to give an allencompassing picture of disability terminology but by using these two months hopes to show trends in the use of the terms.

A separate analysis looked at three other terms, specifically; 'confined to a wheelchair', 'wheelchair-bound' and 'wheelchair user'. The analysis of these terms covered the entire years of 1990, 1995 and 2000, so the findings on those terms were the universe of uses for those years rather than samples. They are included in Table 2.

\section{Findings}

A significant finding from the trend analysis is that these two US agenda-setting newspapers seem to be learning to eliminate the term 'handicapped'. Table 1 shows that The New York Times used the term 38 times in 1990 and by 2000 that had dropped to 26 uses; The Washington Post used the term 32 times in 1990 and by 2000 that had dropped to 17 uses. This change possibly illustrates the inroads the Disability Rights Movement is making in educating news media about preferred terminology. In addition, because 1990 saw the passage of the ADA, many in the media were only beginning to become aware of disability terminology changes. For example, two $1990 \mathrm{New}$ York Times stories in preparation for ski season used phrases such as ski 'clinics for the handicapped' (Nelson, 1990, p. 15) and 'expanded handicapped skiers' program' (Carr, 1990, p. 8). Whereas in 2000, a New York Times story that had several references to 'handicapped children' was headlined 'Parents make toys for disabled children' (Brenner, 2000, p. 22). So there seems to be a transition occurring in the news media to replace the term 'handicapped' with 'disabled' in some instances. In

Table 1. Disability-related terms in The New York Times and Washington Post Terms

Oct-Nov 1990

$(\mathrm{N}=140)^{*}$

Oct-Nov 1995

$(\mathrm{N}=224)^{*}$ 
Oct-Nov 2000

$(\mathrm{N}=186)^{*}$

New York Times New York Times New York Times

'The Disabled' 287141

Disabled person (as adjective) 415961

Become disabled (as adverb) or other 221920

Disability (as noun) 364933

Person with disability/persons with

disabilities

132137

Handicapped (any use not part of

organization's name)

383726

Cripple (noun, referring to disability) 03 (in quotes) 1 (in quote)

Crippled (verb or adverb, referring to

disability)

1060

Washington Post Washington Post Washington Post

'The Disabled' 346644

Disabled person (as adjective) 557081

Become disabled (as adverb) or other 253730

Disability (as noun) 344365

Person with disability/Persons with

disabilities

192445

Handicapped (any use not part of

organization's name)

322117

Cripple (noun, referring to disability) 110

Crippled (verb or adverb, referring to

disability)

1057

* Several terms may appear in one story. $\mathrm{N}=$ number of total stories.

addition, both newspapers appear to understand that the term 'crippled' is no longer appropriate, although The Washington Post used the term occasionally.

Another positive finding is the increased use of the 'people-first' terms, 'person with a disability' or 'people with disabilities'. In the Washington Post, this term increased from 19 references in 1990 to 45 in 2000. Part of this increase is probably due to prevalent use of 'people-first' terminology among government and disability organizations, and the media are using verbatim references to terms given to them by these groups. For example, a Washington Post education story uses the phrase 'students with disabilities', which is probably how the Council for Exceptional Children's report - the source of the story - referred to them (Washington Post, 2000, 
Nov. 7, p. A18.)

However, general disability terminology that is not preferred by the disability community also had increases over the years. Use of the term, 'The Disabled' increased in both newspapers, especially in 1995. The reason this noun phrase is not preferred is that these nouns created from adjectives define people with disabilities in terms of their disabilities, rather than as people first (Longmore, 1985 ). This type of language subjugates people and presents them only in terms of their disability, rather than as multidimensional people. Not unsurprisingly, Dajani (2001) confirmed that a now defunct Disability News Service rarely used 'the disabled' but that The Associated Press used the term more often than 'people with disabilities' or 'disabled people' over a six-month period.

However, it is speculated that most media do not know or understand this problem with the term 'the disabled'. 'The disabled' fits with the norms of journalism because it is shorter than 'people with disabilities' in space-sensitive newspapers. Also, many times the newspapers used 'the disabled' in combination with other groups, such as 'housing for the homeless, the disabled and people with mental problems' in The New York Times (Brenner, 1995, p. 1). These uses of the terms illustrate another problem in how 'the disabled' is used - it seems to be partnered with powerless societal groups. In fact, the majority of US people with disabilities between the ages of 21 and 64 (57\%) are employed; therefore, it is inappropriate to identify them as poor or homeless (US Census, 2002, online).

Finally, the most problematic terminology use in the two newspapers is the continued and increased use of 'wheelchair-bound' and 'confined to a wheelchair'. The AP Stylebook, the 'bible' on language use for print journalists, tells journalists not to write about a person's disability unless it is pertinent to the story (Goldstein, 2002). The Stylebook admonishes writers not to use the terms 'confined to a wheelchair' or 'wheelchair-bound' because 'people use wheelchairs for independent mobility' (Goldstein, 2002, pp. 74-75). Therefore, in using incorrect language about disability, the journalists have rejected some of the rules of their profession. Imbedded cultural beliefs seemed to overtake the professional norms of journalists. Even as recently as the death of Christopher Reeve in October 2004, The Washington Post continued to use 'wheelchair bound' in an editorial about stem cell research and Reeve, and in a story about the arrest of an elderly protestor (Thackeray, 2004, p. A17).

The Washington Post was found to be a prevalent user of the term 'wheelchairbound', with use of the term increasing from nine instances in 1990 to 21 instances in 2000. Although this is a small number for the entire year, the term is never supposed to be used at all. The term is typically used as an adjective to describe someone, such as 'her wheelchair-bound sister' (Toscano, 2000, p. M24) or 'two wheelchair-bound New Yorkers' (Kurtz, 2000, p. A8). The use of 'confined to a 
wheelchair' assigns blame to a disease or medical condition that caused the 'confinement'. For example, the New York Times called 'Carol Rosenwald, frail and confined to a wheelchair by multiple sclerosis' (Ryan, 2000, p. 1).

As language use, both terms are incorrectly applied because confined means 'to keep shut up, as in a prison' and bound means 'tied' (Webster's New World Dictionary of the American Language, 1977), and everyone who uses a wheelchair leaves the chair for activities such as sleeping. When journalists use these terms, they misrepresent disability, as well as showing their misunderstanding of the disability experience. Wheelchairs are not binding or confining but actually increase mobility, speed and ability. For many people, wheelchairs increase their personal freedom (Issacson-Kailes, 1986).

A number of disability studies scholars argue that this inappropriate language use reflects the fears of non-disabled people about disability. Human fears of an 'imperfect body' that might need to use a wheelchair are great. Feminist disability studies scholar Susan Wendell (1989) says that it is more than just fear of physical difference at work here: 'Suffering caused by the body, and the inability to control the body, are despised, pitied, and above all, feared. This fear, experienced individually, is also deeply imbedded in our culture' (Wendell, 1989, p. 112). One study showed that $29 \%$ of Americans surveyed felt wheelchair use was a tragedy (Patterson \& Witten, 1987). Journalists are inculcated with these same cultural fears.

Even in light of these cultural fears, this study of terminology in The Washington Post and New York Times does provide some evidence that journalists are learning to integrate new, more favorable terms into their stories. Both newspapers are using the term, 'wheelchair user' more often. The use of the term more than doubled in The Washington Post and more than tripled in The New York Times. Considering that entire Table 2. Wheelchair-related terms in The New York Times and Washington Post Terms 1990 (complete years) 1995 (complete years) 2000 (complete years) New York Times New York Times New York Times

Wheelchair-bound 121918

Confined to a wheelchair 161421

Wheelchair user 41613

Washington Post Washington Post Washington Post

Wheelchair-bound 91021

Confined to a wheelchair 91310

Wheelchair user 5813

years of stories were analyzed, there is not much use of the term, but the fact that 'wheelchair user' grew in prevalence in 1995 and 2000 means two major newspapers are aware it exists. 


\section{Conclusions}

As with other oppressed groups in society, language is a site of struggle. And for people with disabilities, issues of identity are tied to media labeling. Even the slight improvement of disability terminology in the news media, that is, less use of 'handicapped' and more use of 'wheelchair user', serves to illustrate the growing political influence and identity of the U.S Disability Rights Movement. Susan Scheer, formerly a deputy director in New York's Mayor Office for People with Disabilities, explains that the growth of an educated, professional class of disability rights advocates has meant a more sophisticated approach to changing media coverage of disability issues:

Litigating cases and lobbying elected officials were the traditional techniques that the community used in the past. But now these techniques are used in combination with establishing connections with television, radio, and newspaper reporters and educating them. The language in the news accounts and editorials, although far from perfect, is much improved; for example, 'wheelchair user' is finally beginning to replace 'wheelchair bound.' Also, stories have more balance, and the result is that the public is beginning to understand disability issues. (Susan Scheer, quoted in Fleischer \& Zames, 2001, p. 208)

Although Scheer's comments are slightly more optimistic than this study found, many who follow media reporting are seeing that American journalism has a better understanding of disability topics. The hope is that deep within media practices, changes are percolating - changes that will begin to see people with disabilities and their issues in the same way as other social, cultural, and civil rights issues. This study offers no definitive proof that the media are beginning to understand disability rights and disability terminology, but the trends found do indicate that their labeling of people with disabilities has improved. For example, if the trends found by this study continue, the word 'handicapped' may no longer appear in US news media within a decade or so.

Therefore, studies such as this one that track media labeling of people with disabilities help us understand how far the US news media have come and how far they must go to reach a higher level of disability understanding. This paper illustrates that changes in disability language use within the media can signal a new paradigm in the way people with disabilities will be framed in the future.

\section{Notes}

1. As this paper is about disability terminology in the US media, the preferred term in the USA, 'people with disabilities', will be used. It is understood that other English-speaking countries have other preferred terms. 


\section{References}

Allen, I. L. (1990) Unkind words: ethnic labeling from Redskin to WASP (New York, Bergin \& Garvey).

Barnartt, S., Schriner, K. \& Scotch, R. (2001) Advocacy and political action, in: G. L. Albrecht, K. D. Seelman \& M. Bury (Eds) Handbook of disability studies (Thousand Oaks, CA, Sage), 430-449. Barnes, C. (1992) Disabling imagery and the media: an exploration of the principles for media representations of disabled people (Derby, The British Council of Disabled People).

Barnes, C. \& Mercer, G. (2001) Disability culture: assimilation or inclusion?, in: G. L. Albrecht, K. D. Seelman \& M. Bury (Eds) Handbook of disability studies (Thousand Oaks, CA, Sage), 515-524.

Ben-Moshe, L. (2005) 'Lame idea': disabling language in the classroom, in: Building pedagogical curb cuts: incorporating disability into the university classroom and curriculum (Syracuse, NY, Syracuse University Press), 107-115.

Birenbaum, A. (2000, July-August) Once again, for the first time, people with disabilities are recruited into the workforce, Ragged Edge. Available online at:

http://www.raggededgemagazine.com/0700/0700medge1.htm (accessed 18 October 2002). Blaser, A. (2002) Changing the meaning of 'disability', Ragged Edge, 25-26.

Bolt, B. (1999, July-August) The media don't 'get it' because we don't know what 'it' is, Ragged Edge, p. 24.

Bowe, F. (1978) Handicapping America (New York, Harper \& Row).

Bower, J. (1994) HIV \& disability, The Disability Rag \& Resource, 15(2), 8-14.

Brenner, E. (1995, October 15) Unease persists over housing mandates, New York Times, section 13WC, p. 1.

Brenner, E. (2000. November 26) Parents make toys for disabled children, New York Times, section 14WC, p. 22.

Carr, S. (1990, November 11) Winter in the snow; stretching dollars on the slopes, New York Times, section 5, p. 8.

Casey, R. P. (1992, July 22) Commonwealth of Pennsylvania Governor's Office executive order, (Harrisburg, PA, Commonwealth of Pennsylvania), 1-2.

Clogston, J. (1989) A theoretical framework for studying media portrayal of persons with disabilities, paper presented at the annual meeting of AEJMC, Washington, DC, August. Clogston, J. S. (1990) Disability coverage in 16 newspapers (Louisville, KY, Advocado Press). Clogston, J. (1991) Reporters' attitudes toward and newspaper coverage of persons with disabilities. Ph.D. dissertation., Michigan State University.

Corbett, J. (1996) Bad-mouthing: the language of special needs (Bristol, Falmer Press).

Corker, M. (1998) Disability discourse in a postmodern world, in: T. Shakespeare (Ed.) The Disability Reader (London, Cassell), 221-233.

Corker, M. (1999) New disability discourse, the principle of optimization and social change, in: M. Corker \& S. French (Eds) Disability discourse (Philadelphia, PA, Open University Press). Crowley, M. \& Crowley, M. (1999) Spotlight on handicap, Take our word for it, 66. Available online at: http://www.takeourword.com/Issue066.html (accessed 13 July 2005).

Cumberbatch, G. \& Negrine, R. (1991) Images of disability on television (London, Routledge). Dajani, K. F. (2001) What's in a name? Terms used to refer to people with disabilities, Disability 
Studies Quarterly, 21(3), 196-209.

Entman, R. M. (1993) Framing: toward clarification of a fractured paradigm, Journal of Communication, 43(4), 51-58.

Finkelstein, V. (1980) Attitude and disabled people (New York, World Rehabilitation Fund 47).

Fleischer, D. Z. \& Zames, F. (2001) The Disability Rights Movement: from charity to

confrontation (Philadelphia, PA, Temple University Press).

Goldstein, N. (Ed.) (2002) The Associated Press stylebook and briefing on media law (Cambridge, MA, Perseus).

Haller, B. (1993) Paternalism and protest: coverage of deaf persons, The Washington Post and New York Times, Mass Comm Review, 20, 3-4.

Haller, B. (1995) Disability rights on the public agenda: news media coverage of the Americans with Disabilities Act. Unpublished doctoral dissertation. Temple University, Philadelphia.

Haller, B. (1999a) How the news frames disability: print media coverage of the Americans with Disabilities Act, in: Research in social science and disability (vol. 1) (Rockville, MD, JAI Press). Haller, B. (1999b) News coverage of disability issues: a final report for the Center for an Accessible Society, San Diego Center for an Accessible Society, July.

Haller, B. (2000) If they limp, they lead? News representations and the hierarchy of disability images, in: D. Braithwaite \& T. Thompson (Eds) Handbook of communication and people with disabilities (Mahwah, NJ, Lawrence Erlbaum).

Haller, B. (2001, April 29) Confusing disability and tragedy, The Baltimore Sun, p. 4C.

Isaacson-Kailes, J. (1985) Watch your language, please! Journal of Rehabilitation, 22, 68-69.

Isaacson-Kailes, J. (1990) Language is more than a trivial concern [Self-published article, Los Angeles, CA]. Available online at: http://www.jik.com/resource.html.

Johnson, M. (2000) Make them go away (Louisville, KY, Avocado Press).

Johnstone, C. J. (2004) Disability and identity: personal constructions and formalized supports, Disability Studies Quarterly, 24(4). Available online at: http://www.dsq-sds.org/_articles_html/ 2004/fall/dsq_fall04_johnstone.html (accessed 12 November 2004).

Kurtz, H. (2000, October 20) In the Senate race, what's past is present, Washington Post, p. A8. Liachowitz, C. (1988) Disability as social construct (Philadelphia, PA, University of Pennsylvania Press).

Linton, S. (1998) Claiming disability (New York, New York University Press).

Longmore, P. K. (1985) A note on language and social identity of disabled people, American Behavioral Scientist, 28(3), 419-423.

Louis Harris and Associates, Inc. (1991) Public attitudes toward people with disabilities. National poll conducted for National Organization on Disability (New York, Louis Harris and Associates, Inc.).

Nelson, J. (1990, November 11) Winter in the snow; Breckenridge's wealth of choices, New York Times, section 5, p. 15.

Olien, C., Tichenor, P. \& Donohue, G. (1989) Media and protest, in: L. Grunig (Ed.) Monographs in environmental education and environmental studies (Troy, $\mathrm{OH}$, North American Association for Environmental Education).

Patterson, J. \& Witten, B. (1987) Myths concerning persons with disabilities, Journal of Applied Rehabilitation Counseling, 18(5), 42-44.

Peters, S. (1999) Transforming disability identity through critical literacy and the cultural politics 
of language, in: M. Corker \& S. French (Eds) Disability discourse (Philadelphia, PA, Open University Press).

Ragged Edge (1999, July-August) What we say. What they hear, 19-23.

Reiser, R. (2001, October) Does language matter? Disability Tribune. Available online at: http:// www.daa.org.uk/e_tribune/e_2001_10.htm (accessed 11 July 2005).

Ryan, B. (2000, December 31) Snapshots of their lives, New York Times, Section 14CN, p. 1. Schwartz, J. (1996, July) Local news matters, American Demographics, p. 18.

Scotch, R. K. (1988) Disability as the basis for a social movement: advocacy and politics of definition, Journal of Social Issues, 44(1), 159-172.

Shapiro, J. (1993) No pity. People with disabilities forging a new civil rights movement (New York, Times Books/Random House).

Smith, T. W. (1992) Changing racial labels: from 'colored' to 'Negro' to 'Black' to 'African American', Public Opinion Quarterly, 56, 496-514.

Stewart, C., Smith, C. \& Denton, R. (1994) Persuasion and social movements (3rd edn) (Prospect Heights, IL, Waveland).

Temple University Institute on Disabilities (1992) People first: a language guide. Brochure available from IOD/UAP, Ritter Annex, Temple University, Philadelphia, PA, 19122.

Thackeray, B. (2004, October 30) Wheelchair users not bound, Washington Post, p. A17.

Thomson, R. G. (2001) Seeing the disabled: popular rhetorics of popular photography, in: P. K. Longmore \& L. Umanski (Eds) (2001) The new disability history: American perspectives (New York, New York University Press).

Toscano, M. (2000, December 21) Music rocks into town, Washington Post, p. M24.

US Census (2002) 12th anniversary of Americans With Disabilities Act (press release). Available online at: http://www.census.gov/Press-Release/www/2002/cb02ff11.html (accessed 18 October 2002).

Washington Post (2000, November 7) Extra credit, p. A18.

Watson, S. D. (1993) A study in legislative strategy, in: Implementing the Americans with Disabilities Act (Baltimore, MD, Paul H. Brookes).

Webster's New World Dictionary of the American Language (1977) (New York, Popular Library). Wendell, S. (1989) Toward a feminist theory of disability, Hypatia, 4(2), 104-124.

(1999, July-August) What we say, What they hear, Ragged Edge, pp. 19-23.

(2000, November 7) Extra credit, Washington Post, p. A18. 